\title{
DE ARTISTA A ANDRAGOGO. EXPERIENCIAS EDUCATIVAS DE DOCENCIA NO REGLADA EN CURSOS DIRIGIDOS POR ARTISTAS CONTEMPORÁNEOS.
}

\section{Artist to Andragogic. Educational experiences in teaching non-formal courses run by Contemporary Artists.}

\author{
Rafael Peralbo Cano \\ Facultad de Bellas Artes, Universidad de Granada \\ peralbo@ugr.es \\ Jorge Alberto Durán SuÁrez \\ Facultad de Bellas Artes, Universidad de Granada \\ giorgio@ugr.es \\ Antonio Sorroche Cruz \\ Facultad de Bellas Artes, Universidad de Granada \\ sorroche@ugr.es \\ Carmen Bellido Márquez \\ Facultad de Bellas Artes, Universidad de Granada \\ cbellido@ugr.es \\ Miguel Ángel Moleón VianA \\ Facultad de Bellas Artes, Universidad de Granada \\ mamoleon@ugr.es \\ ISABEL LOZANO RODRÍGUEZ \\ Facultad de Bellas Artes, Universidad de Granada \\ isaxlc@hotmail.com
}

Recibido: 25 de Marzo de 2010.

Aceptado: 22 de junio de 2010.

\begin{abstract}
Resumen:
El presente artículo se centra principalmente en determinar las experiencias andragógicas innovadoras y los vínculos docentes que se establecen entre artistas contemporáneos y alumnos universitarios fuera de la docencia reglada. La estructura del mismo está compuesta por una introducción que de f ne el marco teórico-contextual, los objetivos pretendidos, la metodología de trabajo y el desarrollo analítico de resultados. El análisis de los conceptos didácticos, a consecuencia del conocimiento de tipo andragógico y el artístico, con f guran conceptualmente una didáctica generativa en el contexto de la docencia no reglada. Se delimitan las complejas competencias del profesor universitario, vinculado al Arte, a través del análisis de las experiencias andragógicas en educación superior , el cual, parte inicialmente del modelo de "artista pedagogo" (Barret, 1995; Laferrière, 2000), sumer giéndose en las conf guraciones didácticas alternativas e innovadoras que actualmente encuentran su adecuación con la declaración del 2009 como el Año Internacional de la Creatividad y la Innovación.
\end{abstract}


Palabras clave: Andragogía, arte, educación.

Peralbo Cano, R. Durán Suárez, J.A. Sorroche Cruz, A. Bellido Márquez, C. Moleón Viana, M.A. Lozano Rodríguez, I. 2011: De Artista a Andragogo. Experiencias educativas de docencia no reglada en cursos dirigidos por Artistas Contemporáneos. Arte, Individuo y Sociedad, 23 (1), 29-44.

\begin{abstract}
:
This article focuses mainly on identifying innovative andragogical experiences and educational links established between contemporary artists and university students outside the formal teaching. Its structure consists of an introduction that def nes the theoretical and contextual framework, the objectives pursued, the methodology and analytical development results. The analysis of educational concepts, resulting in the kind of knowledge and artistic andragogic, conceptually form a generative teaching in the context of non-formal teaching. Delimiting the complex responsibilities of university professors, linked toArt, through analysis of experiences in higher education andragogic which, initially part of the model of "artist educator" (Barrett, 1995; Laferrière, 2000), plunging into the innovative and alternative educational settings that are currently the compliance with the declaration of 2009 as the International Year of Creativity and Innovation.
\end{abstract}

Keywords: Andragogy, art, education.

\title{
Sumario:
}

1. Introducción y Objetivos. 2. Metodología. 3. Identidad. El espacio universitario tradicional del docente de Arte. 4. Remediación. Nuevas formas de andragogía artística. 5. Conclusiones. Participación en la experiencia educativa artística. 6. Agradecimientos. 7. Referencias Bibliográf cas.

\section{Introducción y Objetivos.}

La formación de artistas en el mundo occidental ha experimentado una profunda transformación durante las últimas décadas. Esto propicia, desde el campo de las revisiones constantes en materia de enfoques y aprovechamientos educativos de las disciplinas artísticas, estudios diligentes y profundos en verdadero renacimiento humanístico sobre la importancia funcional que posee el cultivo sistemático del mundo del Arte como medio de expresión del individuo y su comunidad (Frega, 2009).

En este sentido, la docencia universitaria se ve en la necesidad de adaptarse a un entorno abierto de colaboración donde la producción y la divulgación del conocimiento no son procesos exclusivos de las instituciones cientí f cas tradicionales. Así mismo, la diversidad de perf les profesionales en la demanda laboral de profesionales titulados en Bellas Artes exige una formación versátil y en continua adaptación. Los artistas y profesionales de artes visuales deben estar capacitados para poner en marcha proyectos, construirse su propio futuro laboral y actuar con gran agilidad de movimientos en el ámbito del ejercicio libre de la profesión. Los Cursos dirigidos por Artistas Contemporáneos, dentro de docencia no reglada, atienden a una especialización que cubre esta realidad profesional, estableciendo puntos de colaboración importantes con otras disciplinas académicas y f guras profesionales reconocidas.

El análisis de los conceptos didácticos nacidos de la génesis entre el saber andragógico y el saber artístico conf guran conceptualmente una didáctica generativa en el contexto de la docencia no reglada. LaAndragogía, entendida ésta como la disciplina 
que se ocupa de la educación y el aprendizaje del adulto (a diferencia de la Pedagogía que se aplica a la educación del niño), def ne al docente como el guía y el facilitador que planif ca, administra y dirige. Como estrategias metodológicas utiliza la enseñanza, aprendizaje y autoaprendizaje, basado fundamentalmente en el intercambio de experiencias.

En el ámbito Artístico, este sistema se desarrolla a través de una praxis fundamentada en los principios de participación y horizontalidad, cuyo proceso, al ser orientado con características sinérgicas por el Artista facilitador del aprendizaje, permite incrementar el pensamiento, la autogestión, la calidad de vida, y la creatividad del resto de participantes, con el propósito de proporcionarle una oportunidad para que logre su autorrealización. La participación denota al estudiante no como mero receptor , sino como sujeto capaz de interactuar con sus compañeros, intercambiando experiencias que ayuden a la mejor asimilación del conocimiento artístico. Ello propicia que el estudiante participante pueda tomar decisiones en conjunto con otros estudiantes participantes y actuar con estos en la ejecución de un trabajo o de una tarea común. El hecho de enfrentarse a nuevos retos, implica necesariamente una siner gia de esfuerzos centrados en lograr de manera efectiva la meta trazada. Una vez obtenidos los resultados, se enriquecen las experiencias de aprendizaje.

Al presentar el papel del artista andragogo dentro de este contexto, se pretende analizar la utilización de conocimientos, técnicas e instrumentos propios del arte y de la docencia artística, en el desarrollo de Cursos dirigidos por Artistas Contemporáneos, que posibilite una implicación social amplia donde el aspecto lúdico, dinámico y dramático del trabajo del facilitador puede cambiar la forma de pensar de los que intervienen en estos Cursos. Así, entre otros objetivos, podemos reseñar los siguientes: mostrar el pensamiento, la percepción y las prácticas del profesorado universitario vinculado con el Arte, reconocer y visualizar dimensiones innovadoras de enseñanza por parte deArtistas Contemporáneos para una re-conceptualización de la práctica de la enseñanza universitaria no reglada, recuperar e interpretar las concepciones y prácticas del artista andragogo, analizar las relaciones arte-conocimiento-forma-didáctica y las categorías emergentes individuales y grupales y elaborar líneas y propuestas de estudio, análisis y re f exión acerca de la docencia universitaria no reglada así como de otros ámbitos o campos de conocimiento actuales.

\section{Metodología.}

Este trabajo responde a la búsqueda de escenarios complementarios donde los conocimientos andragógico y artístico se encuentren y generen saberes didácticos movilizando la creatividad racional, intuitiva e integradora, que atiende a la perspectiva de Morín (2001), relacionada con el principio dialógico al entender los elementos antagónicos como complementarios. En estos escenarios pueden con fuir diversas interpretaciones complementarias y diferentes lenguajes. Concretamente, en este es- 
cenario extrauniversitario centrado en los temas artísticos, cualquier aproximación buscando cualquier tipo de excelencia o singularidad, rodea un macro concepto que no es más que una construcción de saberes (V ilar, 1997) susceptible de ser tratado desde muy diversas perspectivas.

En este sentido, se adopta para este estudio una forma calidoscópica, rizomática, en la que práctica, teoría, educación y arte se entrecruzan, determinando el orden y la estructura del estudio. Con ello la aproximación al campo es doble: en primer lugar creando un marco inductivo-deductivo pertinente, útil y adecuado y, en segundo lugar, desarrollando y analizando un caso del estudio, el Taller Provincial de Bellas Artes que desarrolla la Diputación de Jaén, dirigido por el reconocido artista plástico Santiago Ydáñez.

\section{Identidad. El espacio universitario tradicional del docente de Arte.}

Como describe el artículo titulado Ética y formación Universitaria (Martínez, et al. 2002), las universidades y su profesorado están abiertos a la innovación, al pensamiento crítico, al progreso y a la búsqueda de rigor y de verdad, pero a la vez son conservadoras, cuidan la tradición y no arriesgan en sus estilos de hacer y de ejercer la docencia. Los sistemas docentes y educativos vigentes, inmersos en la idiosincrasia propia de la tradición andragógica tradicional, considera que la adquisición de conocimientos se realiza principalmente dentro de la docencia reglada, entendida ésta como medio de transformación y principal fuente de información para el alumno. Ello posibilita que el profesor se convierta en transmisor de conocimientos, dirigiendo sus objetivos a su tarea docente, lo que conlleva una infravaloración del desarrollo de habilidades por parte del alumno, o lo que es lo mismo, el profesor actúa como parte activa mientras el educando la pasiva, un receptor de ideas que recibe solo una enseñanza empírica e incluso memorística.

La forma de organización social del aula y de los estilos de aprendizaje debe adaptarse a todo tipo de enseñanza superior que pretenda incidir en los niveles y objetivos que venimos presentando como deseables en un modelo de sociedad de la información, el conocimiento y las tecnologías como la nuestra. Resulta necesario considerar el aula como lugar en el que desarrollar procesos en los que se gestionen de principio a $\mathrm{f}$ n situaciones de enseñanza y de aprendizaje de naturaleza estratégica, donde no solamente se aprendan unos contenidos, sino que se fomente el cómo aprenderlos y ser consciente del proceso seguido en su aprendizaje (Nisbet y Shumcksmith, 1987; Monereo y Castelló, 1997).

En referencia a la naturaleza de las actividades y tomando en cuenta que defendemos un aprendizaje estratégico que tenga que ver con la meta cognición, son per tinentes aquellas actividades que involucren al estudiante de una forma activa y responsable, y donde su quehacer tenga un peso importante en el desarrollo de la sesión o de las sesiones que dure el proceso formativo. Las sesiones de aula deben repre- 
sentar verdaderas comunidades de aprendizaje con un gestor del proceso, como es el docente, de manera que cada persona pueda desarrollar sus propias estrategias heurísticas de aprendizaje, al tiempo que se comparte entre todo el grupo una manera de trabajar y de aprender y un discurso propio y concreto de esa comunidad de aprendizaje (Mercer, 2001). Si nos referimos a la secuenciación de las actividades de enseñanza y de aprendizaje, se trata de que se desarrollen de una manera organizada y coherente, de forma que se vaya de menos a más hacia la autonomía y el control responsable de la actividad del estudiante. De esta forma, proponemos situar las actividades más dependientes del docente al principio de las secuencias del proceso formativo, y las más autónomas, independientes y complejas al f nal (Martínez, et al. 2002).

\section{Remediación. Nuevas formas de andragogía artística.}

Las innovaciones y los cambios en el ámbito universitario, sobre todo cuando no es obvio el perfeccionamiento que comportan, pueden alcanzarse mejor mediante la persuasión y la implicación en proyectos compartidos que mediante la exigencia nor mativa. Bajo esta premisa surge el papel activo del profesorado-artista dentro de las facultades de Bellas Artes. En el análisis de esta f gura situada en la institución universitaria se ha tenido presente que las instituciones son entramados de convenciones sociales, productos materiales y simbólicos de nuestra imaginación instituyente (Castoriadis, 1993) formados por personas que ocupan diversos lugares. En este sentido, se pretende un acercamiento a un imaginario instituyente desde una perspectiva concreta de un colectivo docente.

A diferencia de la Andragogía tradicional analizada anteriormente, las tendencias contemporáneas acentúan el papel social que debe tener la universidad: formar para vivir dentro de un medio social. La tarea del profesor ya es de conductor, propicia y dirige la adquisición de aprendizajes, el educando asume un papel activo, y el proceso de enseñanza-aprendizaje es recíproco y cumple con las necesidades e intereses del alumno. Se práctica el método inductivo-deductivo y ahora el alumno es el centro del proceso educativo desempeñándose un incremento del papel autodidacta y auto instructor del mismo.

Por otra parte, representa una mirada al profesorado universitario partiendo de modelos clásicos para adentrarse en la f gura del andragogo-artista considerado en este trabajo como intelectual-creador y supone, desde el punto de vista profesional, un acercamiento a la formación y visión social a través de discursos alternativos, no estandarizados ni generalizados. La acción didáctica emer ge de la doble situación simbólica e imaginaria que forma parte de este saber andragógico en el que la dimensión artística no es un recurso más sino que opera con sensibilidades y lenguajes diversos. El saber andragógico es la forma que emerge de un tipo de relación que es instituyente del saber, cobrando un valor epistemológico que atiende al hecho en sí 
mismo (Montané, 2009). La forma que emer ge en una situación educativa responde al principio de que el todo es más que la suma de sus partes:

esta es, seguramente, la característica más importante que se pueda retener: la forma agrega, reúne, moldea una unicidad, dejando a cada elemento la autonomía que le es propia, constituyendo al mismo tiempo una innegable or ganicidad, donde sombra y luz, funcionamiento y disfuncionamiento, orden y desorden, lo visible y lo invisible entran en sinergia... (Maffesoli, 1997).

Si se asimila andragogía y arte, y al mismo tiempo se entiende el arte como organismo vivo (V ygotsky, 1970; Daniels, 2003), la relación contenido/forma se vuelve densa y compleja hasta fundirse en un todo interdependiente. Se puede partir de principios o preceptos tales como la visualización de la situación andragógica como posibilidad el punto de origen de la cual no es el dé f cit del alumnado sino la potencia de sus posibilidades. Esta situación, más colaborativa que dirigida, trabaja con distintos lenguajes: verbales, no verbales, corporales, tecnológicos, etcétera, todo dentro del imaginario y la visualización, haciendo de ella una situación transdisciplinar y compleja.

\section{Conclusiones. Participación en la experiencia educativa artística.}

La siguiente experiencia, realizada durante la primera quincena de los meses de agosto de 2008 y 2009 respectivamente, se encuadraría dentro de lo que se conoce como docencia no reglada (o extra universitaria), la cual podría def nirse como "toda actividad organizada, sistemática, educativa, realizada fuera del marco del sistema of cial, para facilitar ciertas clases de aprendizajes a subgrupos particulares de la población tanto adultos como niños" (Coombs, et al. 1973).

En el caso concreto del Taller Provincial de Bellas Artes que se desarrolla dentro las fechas indicadas en la localidad de Quesada (Jaén), la dirección recae en un artista plástico no vinculado a la docencia universitaria, si bien este taller está dirigido a alumnos de las Facultades de Bellas Artes españolas. Santiago Ydáñez es un artista plástico nacido en Puente de Génave, Jaén, en1969. Estudió Bellas Artes en la Universidad de Granada y ha realizado talleres entre otros con Juan Genovés. Ha recibido importantes distinciones y es actualmente uno de los pintores jóvenes españoles con mayor proyección internacional. Este taller de Bellas Artes, que nace con el objeto de alentar a los jóvenes creadores en el campo de las diversas artes, está regido por el principio de la interdisciplinariedad y el análisis integral del fenómeno artístico, si bien posee carácter monográf co por razones geográf cas y de aprovechamiento (Fig. 1). 


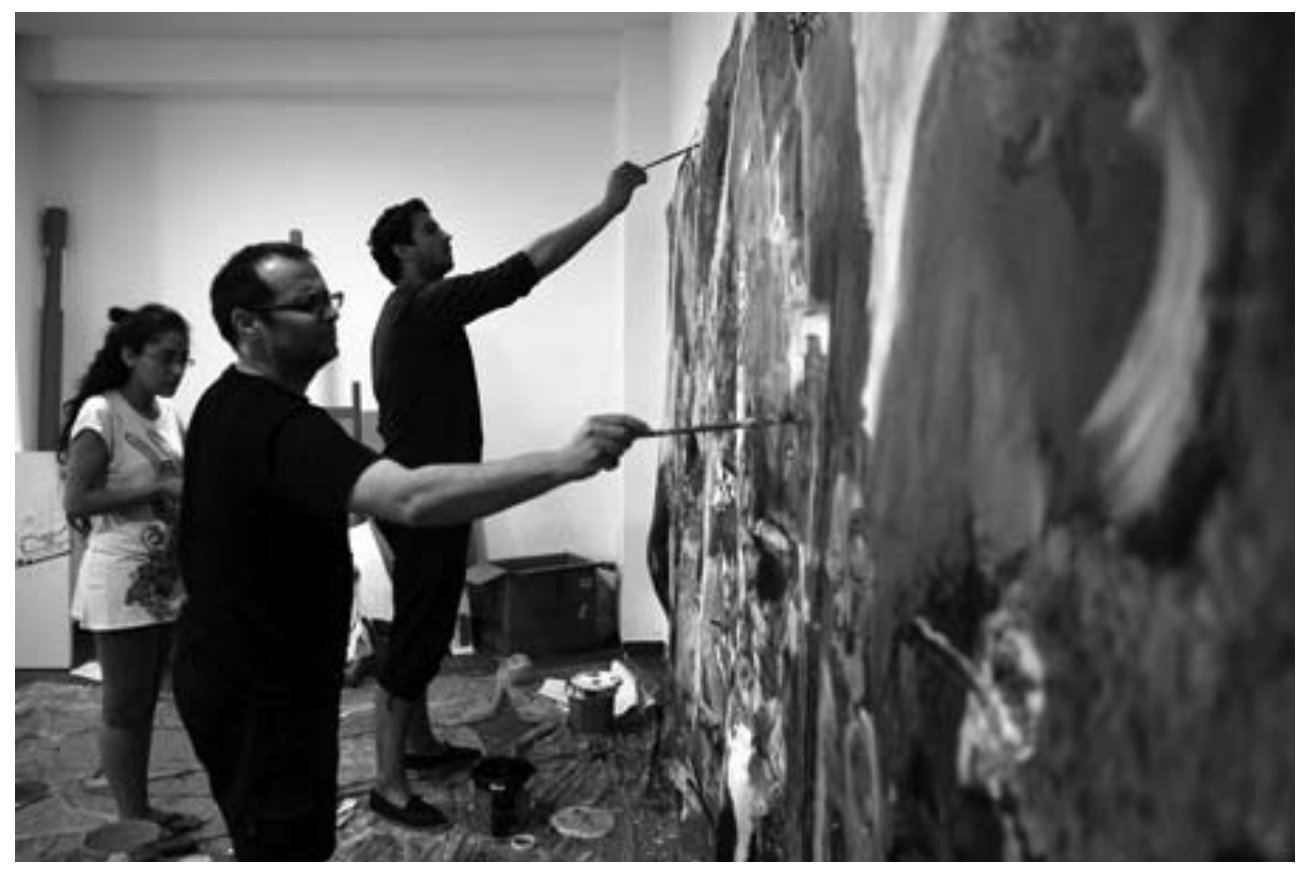

Figura.1.Inicio del trabajo en paralelo de Santiago Ydáñez con sus alumnos.

La labor andragógica realizada en el marco de esta actividad por parte de este artista, dif ere en gran medida de la f gura del profesor dentro de las instituciones universitarias. Este curso, si hubiera de ser encuadrado, sería dentro de las tradiciones de formación docente; desde luego ni en la académica ni en la técnica, puesto que es precisamente lo que pretenden evitar: enseñar lo preestablecido o tradicional (enseñanza como transmisión cultural) e impedir al alumno que investigue por sí solo en las técnicas, materiales, etc. (Fig. 2). La crítica es entendida como la imposición de una minoría supuestamente iniciada, y en arte no debe haber ni inicio ni f n, tan sólo proceso. Parece pues, que la andragogía empleada plantea un modelo de formación del alumno en el que se incide bastante poco en lo que sería la relación de enseñanza-aprendizaje en favor de una observación del "auto aprendizaje" (Lowenfeld y Lambert, 1977). No se contempla la evaluación pero sí la evolución, por supuesto con la ayuda del facilitador y las propias cualidades del alumno.

Se parte de la base de que a los alumnos seleccionados se les exige un nivel técnico y artístico avanzado como corresponde a los últimos cursos de las Licenciaturas en Bellas Artes. Este contexto posibilita que, por la madurez de los participantes en el Taller, las acciones que se desarrollan durante el mismo estén de f nidas más por un compendio de actividades prácticas y especulativas, alrededor de su trabajo, que por la elaboración clásica de obras denominadas artísticas. El contexto general, por 


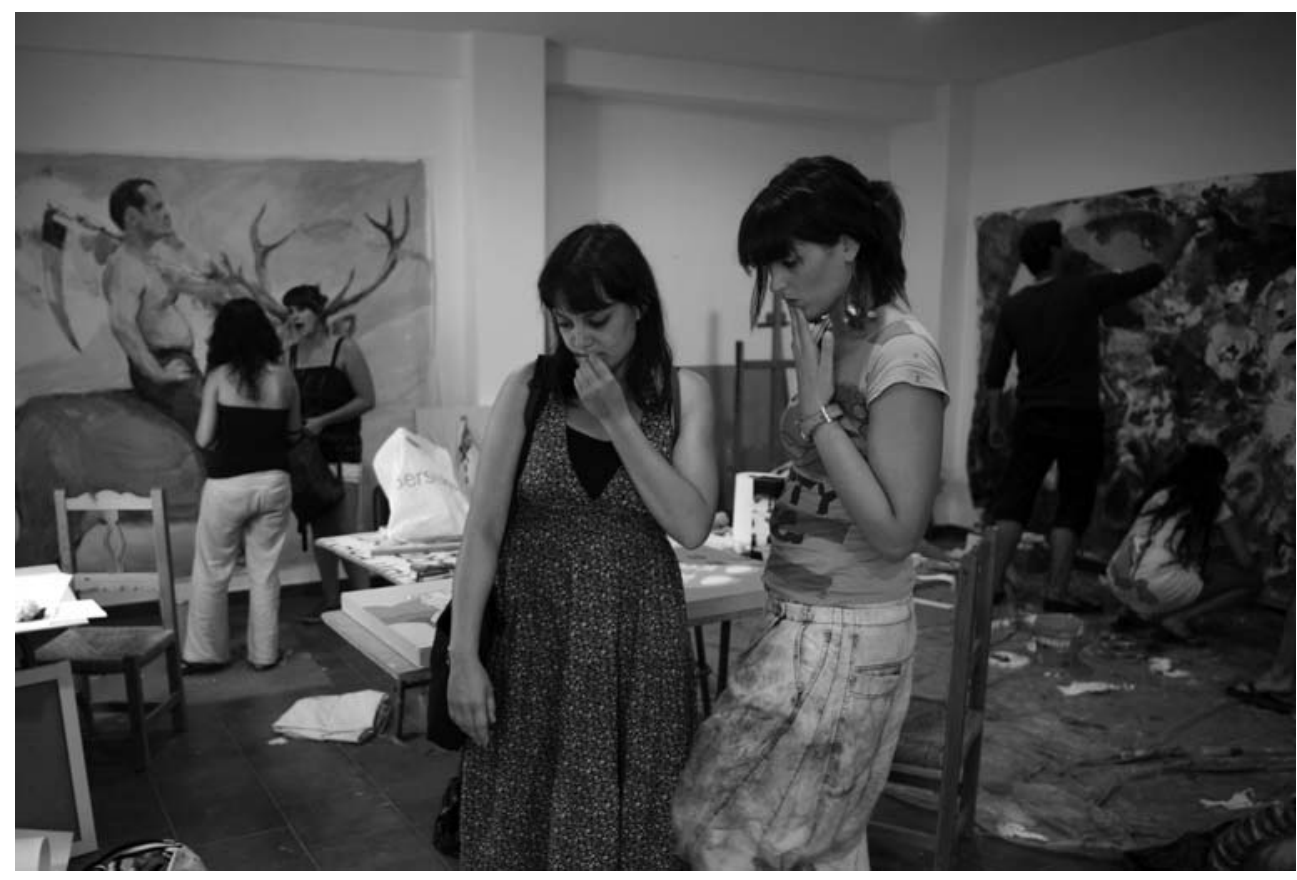

Figura.2. Espacio para la acción directa, espacio para la ref exión.

tanto, propicia que los participantes entiendan, practiquen y re fexionen grupalmente sobre Arte en sus diversos aspectos culturales, personales y profesionales, af $\mathrm{n}$ de que adquieran una comprensión global de contenidos, procedimientos y metodologías posibles (Fig. 3). Dentro de este proceso, la f gura del facilitador-artista actúa como base motivadora para una posterior profundización personal que les permita afrontar las múltiples alternativas con que se encontrarán en su desarrollo artístico. En esta f gura se reconoce un saber "docente" que incorpora un pensamiento, unas estrategias y unas técnicas determinadas, susceptibles de ser estudiadas y que el ar tista conoce y maneja cotidianamente. Efectivamente, los artistas pueden aportar otra manera de ver las cosas, puesto que ref exionan sobre matices que pasan desapercibidos para gran parte del profesorado universitario, inventando soluciones inusuales e imaginando nuevas realidades dentro del ámbito artístico.

Estas transformaciones se evidencian en las de f niciones que hacen del artista "como si" utilizado por Octavi Rofes (2007) y el de artista, utilizado por el artista brasileño Ricardo Bausman. El artista "como si” según Rofes es aquel que construye su trabajo a partir de la apropiación o adopción de metodologías y estrategias pertenecientes a otras disciplinas no artísticas. A partir de su def nición, podríamos def nir esta estrategia como un "Ready Made " metodológico (Fig. 4). 


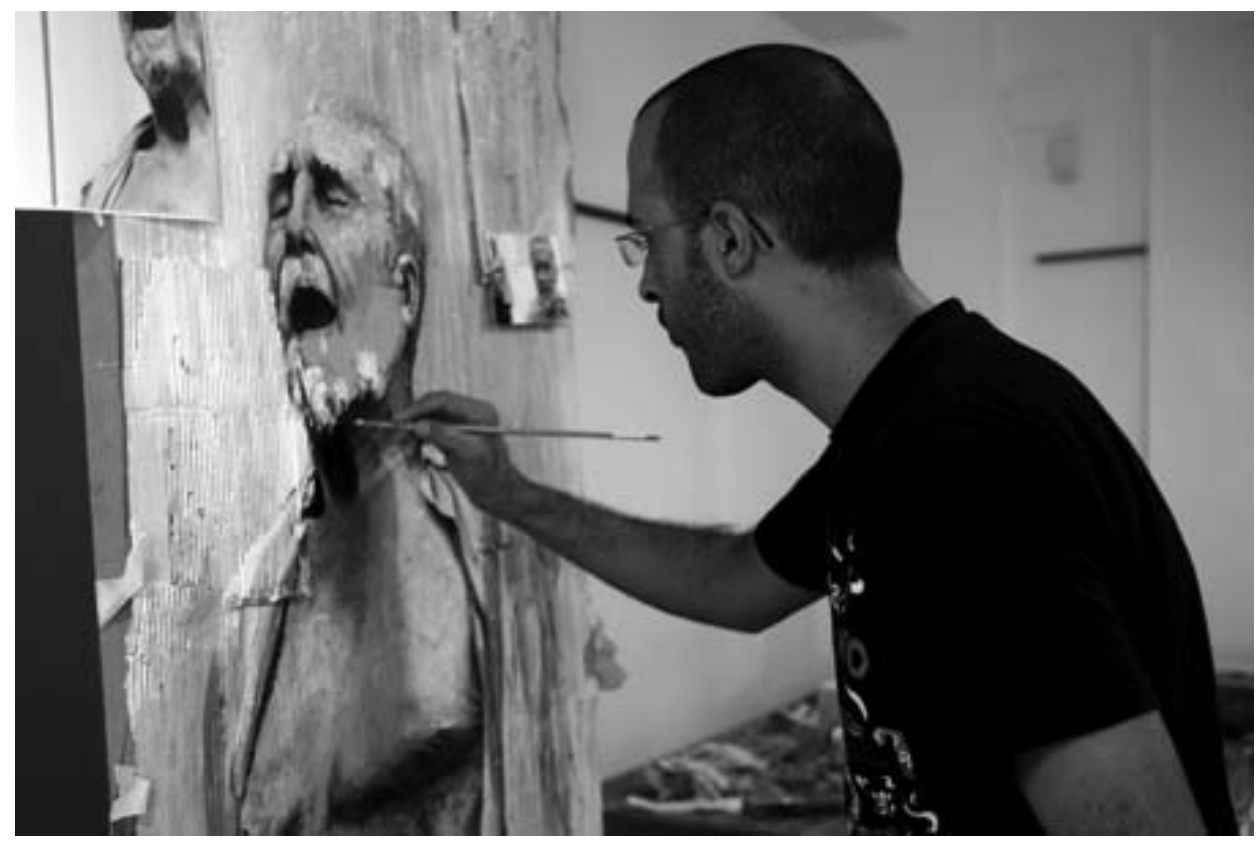

Figura 3. El cuestionamiento del rol de "artista": prácticas tradicionales, conceptos nuevos.

En este sentido, no es de extrañar que durante los últimos años, hayan sugido iniciativas de artistas, como es el caso de SantiagoYdáñez, que adquieren el compromiso de asumir responsabilidades colectivas sobre la comunidad cultural. La ausencia de espacios dedicados al arte que pudieran contener sus producciones e intereses ha hecho que muchos de ellos tomen la decisión de generar nuevos contextos de exhibición, de perfeccionamiento o de expansión: lugares para el desarrollo de propuestas culturales, residencias de artistas, cursos o talleres, con la intención de expandir su campo de acción como una estrategia básicamente de supervivencia artística.

En otras palabras, se trata de un artista que no sólo desarrolla un rol social a través de su obra, sino también con su hacer, ligado a otras experiencias, tales como la gestión, la docencia, la producción teórica, etc. Esta característica está muy extendida en los artistas visuales y plásticos actuales, que al igual que Santiago Ydáñez, se ven involucrados en procesos de selección, dirección y evaluación de proyectos de otros artistas, porque el problema andragógico de los artistas no consiste en responder a las preguntas, sino en ayudar a imaginar, a sugerir caminos que conduzcan a las preguntas y que estas preguntas ayuden a la persona a tener apertura a la comprensión, o la justif cación (Figs. 5 y 6). En suma, debe ser una pedagogía de la sorpresa y de la interrogación que ponga a los participantes en situación de investigación y les dé la oportunidad de encontrar sus propias respuestas. 


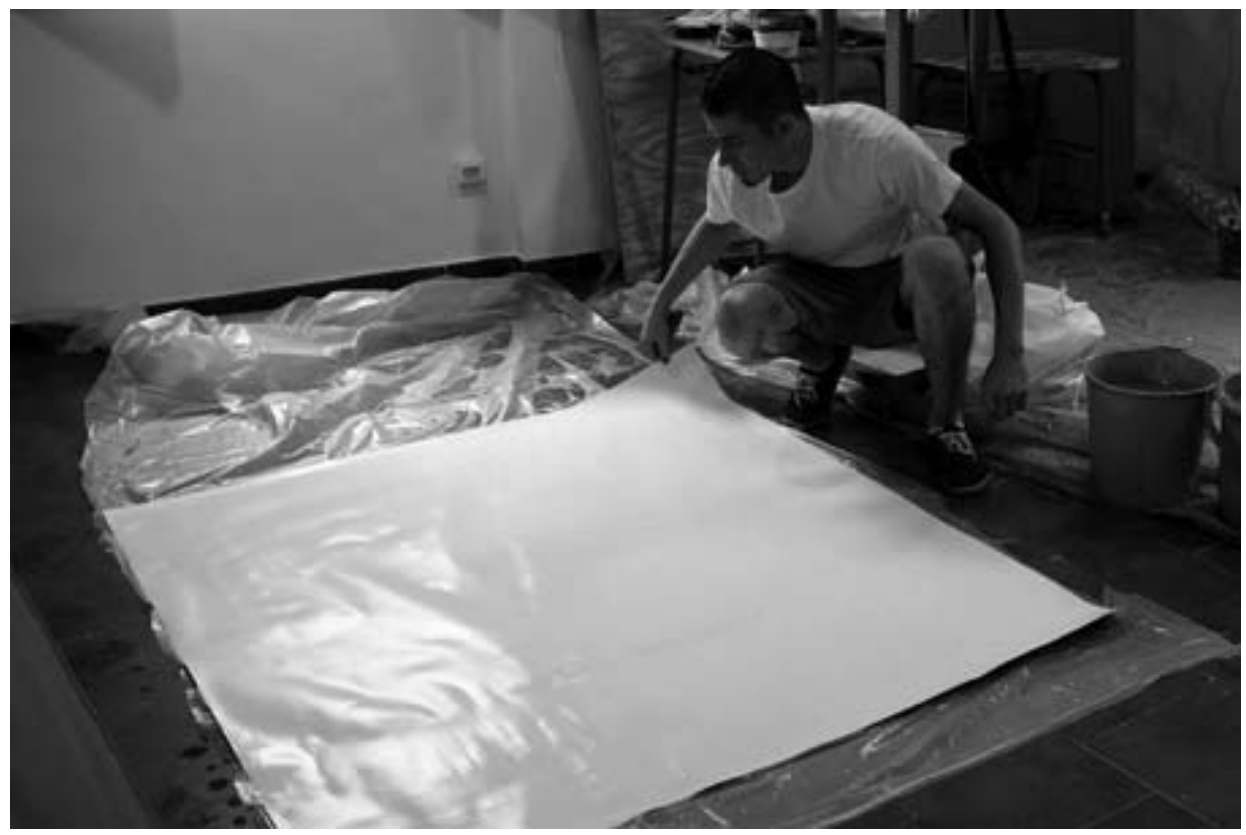

Figura.4. Interactuación de prácticas y técnicas (Ready Made metodológico).

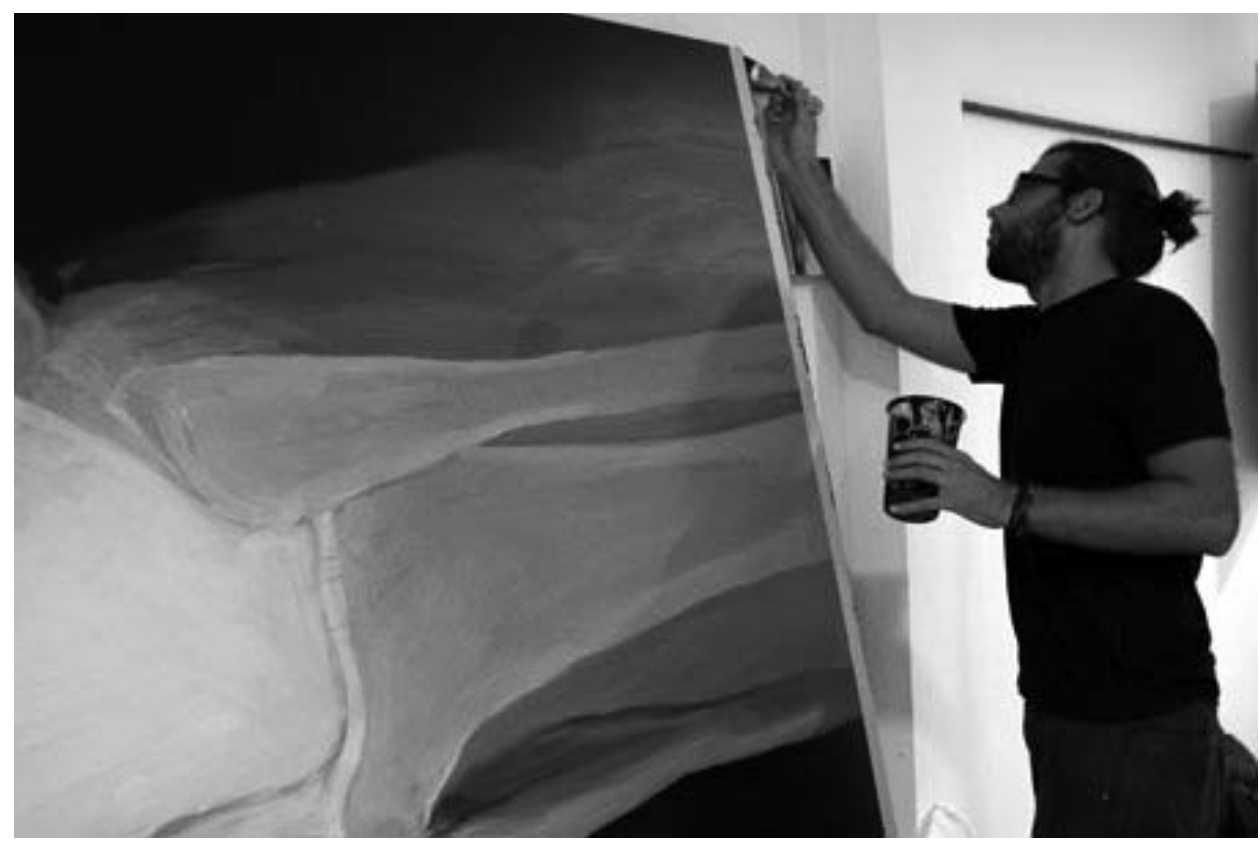

Figura.5. Imaginar y descubrir: apertura de nuevas preguntas. 
Por eso, estos talleres son abiertos y distintos, nunca estereotipados, donde el imprevisto, la repercusión y el cuestionamiento permanente llevan a los participantes a imaginar y encontrar nuevas soluciones constantemente. En este sentido, los recursos metodológicos aplicados porYdáñez comprenden variables determinadas por la importancia de las prácticas en los procesos de enseñanza-aprendizaje, por lo que es posible encontrar diversas técnicas de trabajo personal y grupal. Así, una de las primeras actividades que se desarrolla en grupo es una charla-coloquio, con apoyo de métodos audiovisuales, sobre diversas técnicas de expresión artística, y el intercambio de diferentes actitudes y motivaciones con que confrontar el trabajo a desarrollar. Los participantes plantean sus inquietudes artísticas y ponen en común los criterios de elaboración y puesta en práctica de su programa de realización plástica dentro del ámbito delTaller. Se pone de manif esto, igualmente, la reestructuración de conceptos e ideas preconcebidas sobre el Arte, así como el desarrollo de criterios estéticos a partir de la ref exión sobre la imagen visual y las producciones artísticas de cada uno de los asistentes.

A lo largo de la experiencia, el intercambio de ideas es constante entre los diversos equipos que se conforman de forma natural, bien por proximidad conceptual y af nidad, o bien por proximidad física al compartir los espacios ofertados por los or ganizadores para la realización del Taller. Si bien cada artista posee independencia absoluta en el desarrollo de su actividad artística, Ydáñez propone un nexo común lógico ligado al contexto natural y humano del lugar de realización del Taller (la localidad Jienense de Quesada), y a la f gura y obra del renombrado el pintor Rafael Zabaleta, natural de la localidad. De hecho, una de las primeras salidas que realiza el grupo es al Museo Rafael Zabaleta, un moderno y contundente edf cio que alberga la colección que el pintor donó, compuesta por 112 óleos, varias acuarelas y casi 500 dibujos, viéndose incrementada por la creación, años más tarde, de la Sala Amigos de Zabaleta en homenaje al pintor . Artistas de prestigio como Picasso, Miró, Perceval, Solana, Tápies, Benjamín Palencia o Guinovart, donaron sus obras para el Museo Zabaleta, además de incluir, actualmente otras cuatro colecciones más de arte moderno donadas por diferentes personalidades.

Este contexto propicia la realización, por parte de los participantes, de decenas de obras con técnicas y motivaciones diversas en el ámbito de taller . El trabajo incesante del grupo, el cual ocupa 9 ó 10 horas diarias, actúa de incentivo hacia el alumno para que cimente lo asimilado. La f gura del facilitador-artista marca las pautas necesarias para que logre resolver por sí mismo problemas conceptuales y técnicos concretos, ayudando en la capacitación y orientación en el desarrollo de su actividad artística, dentro del marco del Taller.

Independientemente de esta metodología, Santiago Ydáñez propone además proyectos globalizadores para realizar en equipo, como es el caso de una gran pintura colectiva de $2 \times 6 \mathrm{~m}$. Esta actividad conlleva una preparación y planif cación conjunta previa para la elaboración de una obra original conforme a los parámetros establecidos al comienzo del Taller y con la participación activa de todos los miembros del equipo. Dicha obra, al igual que una selecta selección de obras unipersonales que cada uno de los participantes 
realiza, son expuestas al f nalizar el Taller en la localidad de Quesada y sometidas al juicio de los vecinos y visitantes. Además, transcurridos unos meses, las obras son llevadas a la Diputación de Jaén donde se organiza una gran Exposición con catálogo para su muestra pública y difusión en las instalaciones de dicha institución, todo ello bajo la supervisión del Director del Taller.

Esta actividad actúa en gran medida como rea f rmación del trabajo desarrollado durante el taller, siendo valorada muy positivamente por el alumnado participante, según se recoge en la puesta en comúnf nal y el cuestionario de evaluación que emite la propia Diputación de Jaén.

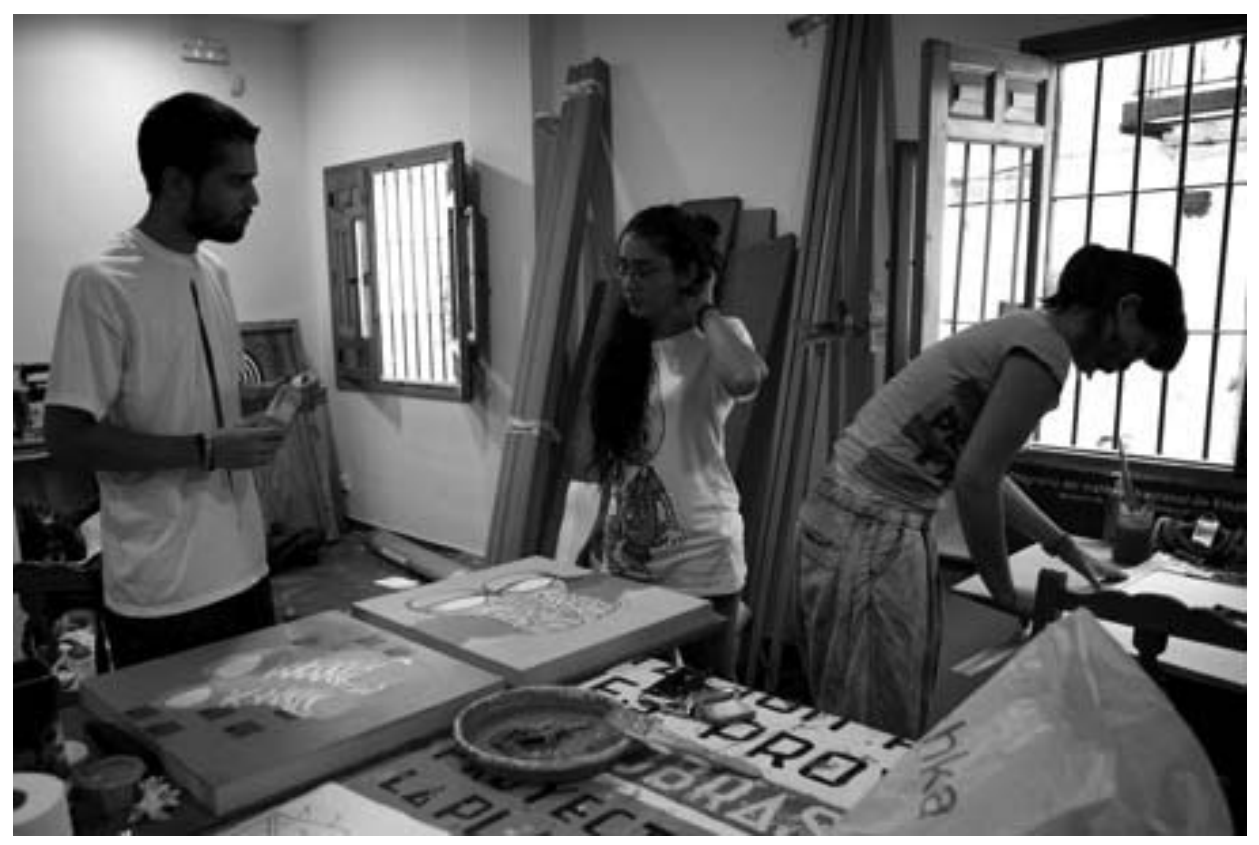

Figura.6. Sorpresas e interrogaciones: las propias inquietudes, las propias respuestas.

En la puesta en común se analizan diversos aspectos conceptuales del Taller, los criterios de desarrollo y los resultados obtenidos desde un punto de vista plástico. De todo ello se redacta una memoria que obra en poder de la Diputación de Jaén. Del mismo modo, los resultados del cuestionario de evaluación que emite la misma entidad ponen de manif esto la labor desarrollada por el artista que dirige ellaller, valorando su actitud, la metodología docente, los objetivos desarrollados, la dirección y coordinación de las actividades y la implicación en todas y cada una de las funciones que desempeña tanto dentro como fuera de la enseñanza propiamente dicha. Por todo ello, la labor del facilitador-artista no sólo se desarrolla dentro de las directrices propias del Taller Artístico, sino que las ideas son cuestionadas en cada una de las actividades diarias sea cual sea su naturaleza. Desde ese punto de vista y con laf nalidad 
de eliminar los prejuicios, es importante mirar escuchar, sentir, tocar y saborear antes de enjuiciar, o imponer ideas. Como decía A. Camus (Sagi, 2002) "Hay que vivir antes de testimoniar". Para alcanzar este eje, el enseñante debe recibir una formación específ ca, a la manera de un artista-pedagogo que se de f na como un ser creativo: una persona que sepa utilizar al máximo todas las propiedades sensoriales, afectivas y cognitivas de su or ganismo en su entorno (Fig. 7). Lo verdaderamente creativo necesita del placer que se encuentra en el trabajo y en la vida y no en la obligación de trabajar o de vivir. La mejor forma para alcanzar un objetivo es olvidarlo. Como André Gide reconoce (1966), "hay que enseñar el fervor de que la vida es una fruta llena de sabores para labios llenos de deseos". Viajar, compartir, inventar cosas, descubrir, hacer la práctica antes de ref exionar sobre ella, eso permite una apertura más amplia a la comprensión del hecho artístico y las experiencias vitales que posibilitan adquirir el propio saber sobre nosotros mismos y sobre el mundo (Fig. 8).

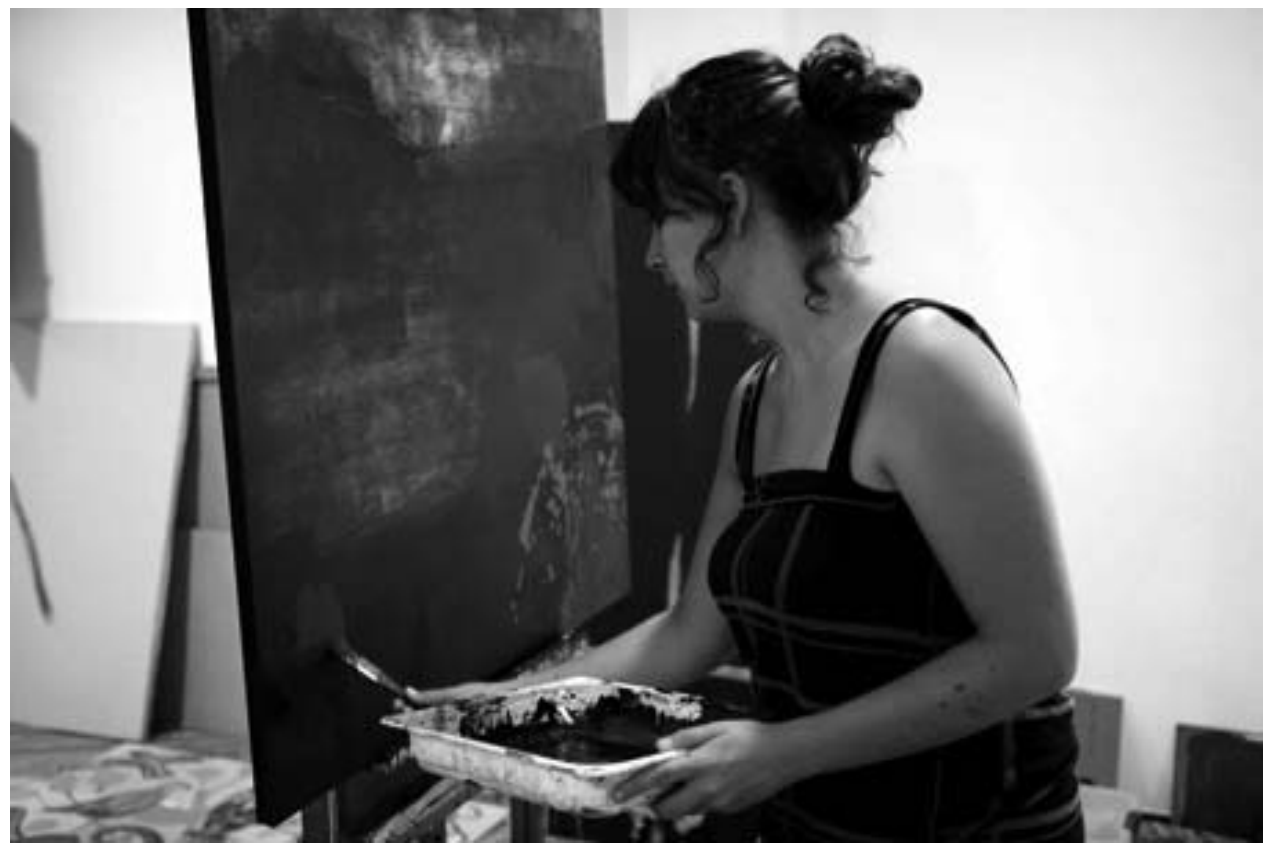

Figura.7. Lo sensorial, afectivo y cognitivo como método de trabajo e interactuación.

\section{Agradecimientos}

Los resultados de investigación presentados en este artículo han sido co f nanciados gracias al Proyecto de Investigación MAT 2006-00308 (Ministerio de Ciencia e Innovación) y del Grupo de Investigación HUM 629 de la Junta de Andalucía. 


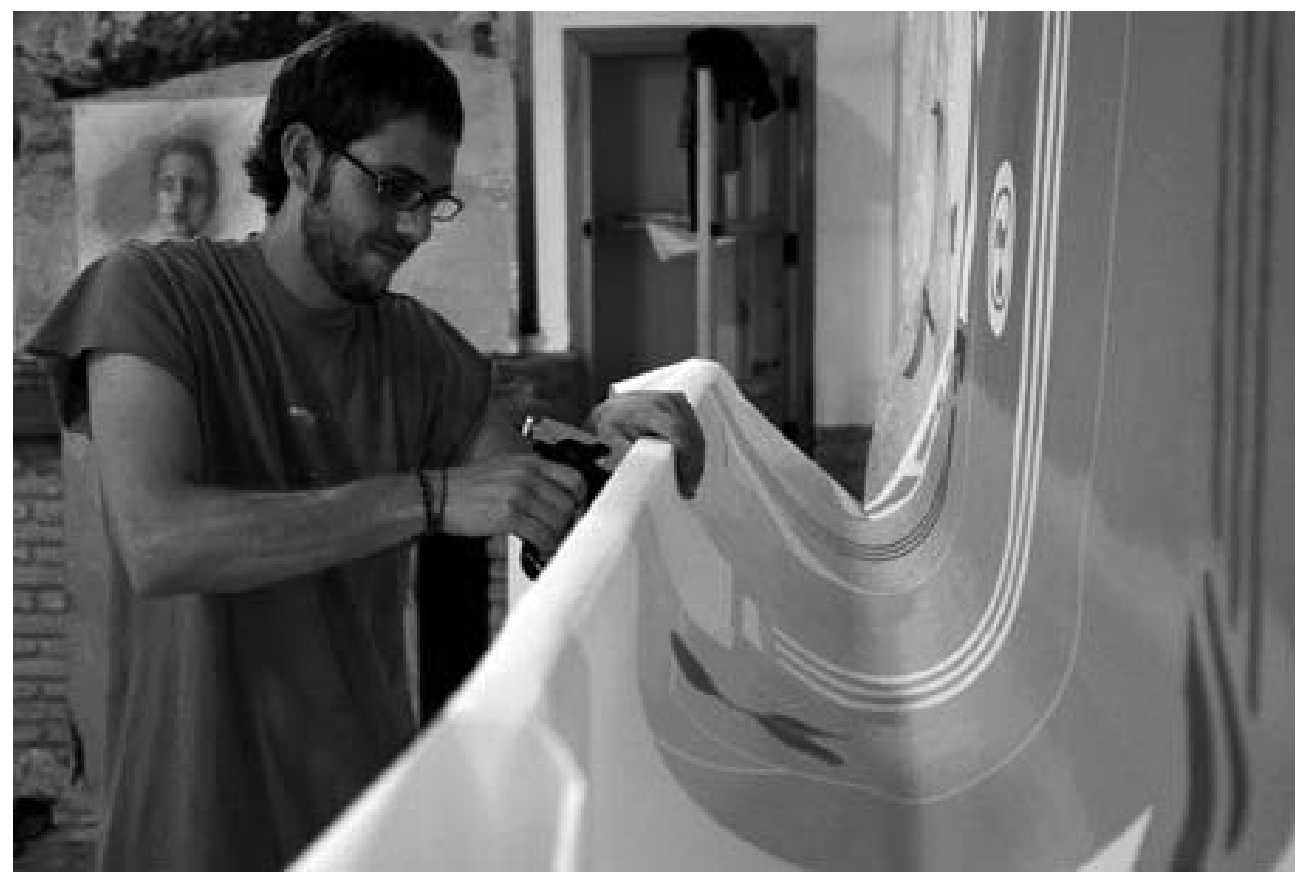

Figura 8. La apertura del hecho artístico y la experiencia vital.

\section{Referencias Bibliográficas.}

Barret, G. 1995: Pedagogía de la situación en expresión dramática y educación. Quebec. Recherche en Expression.

Castoriadis, C. 1993: El mundo fragmentado. Montevideo. Nordan Comunidad.

Coombs, Ph. H; Prosser, R. C. y Ahmed, M. 1973: New paths to learning: for rural children and youth. International council for educational development. New York. Publications Essex.

Daniels, H. 2003: Vygotsky y la pedagogía. Barcelona. Paidós.

Frega, A. L. 1998: Preparación de los artistas como educadores profesionales: necesidades y desafíos. La formación docente en debate (162-166). Buenos Aires. Academia Nacional de Educación

Laferrière, G. 2000: Sesiones de trabajo con los pedagogos de hoy. Ciudad Real. Naque.

Lowenfeld, V. y Lambert, W. 1977: Desarrollo de la capacidad creadora. Buenos Aires, Kapelusz.

Maffesoli, M. 1997: Elogio de la razón sensible: una visión intuitiva del mundo contemporáneo. Barcelona: Paidós.

Martínez, M; Buxarrais, M. R. y Esteban, F . 2002: La universidad como espacio de aprendizaje ético. Revista Iberoamericana de Educación, 29, 17-43.

Mercer, N. 2001: Palabras y mentes. Cómo usamos el lenguaje para pensar juntos. Barcelona, Paidós. 
Monereo, C. y Castelló, M. 1997Las estrategias de aprendizaje. Cómo incorporarlas a la práctica educativa. Barcelona, EDEBÉ.

Montané López, A. 2009: Profesores-artistas y didáctica generativa: Experiencias educativas en la universidad. Universitat de Barcelona.

Morín, E. 2001:Los siete saberes necesarios para la educación del futuro. Barcelona. Paidós.

Nisbet, J. y Shucksmith, J. 1987: Estrategias de aprendizaje. Madrid, Santillana.

Rofes, O. 2007: Contenedores rituales y públicos imaginarios. MDE.

Sagi, A. 2002: Albert Camus and the philosophy of the Absurd. Amsterdam-New York. Rodopi.

Vilar, S. 1997: La nueva racionalidad. Comprender la complejidad con métodos transdisciplinarios. Barcelona: Kairós.

Vygotsky, L. S. 1970: Psicología del arte. Barcelona. Barral. 
